\title{
EFFECT OF HARVESTING TIME ON MILLING YIELD AND GRAIN BREAKAGE FOR EGYPTIAN PADDY RICE
}

\author{
M. E. Yehia* and Ahmed R. Khatab*
}

\begin{abstract}
The effect of harvesting time on rice sensory and physio-chemical properties not well understood. Timing of harvesting rice with meteorological conditions can allow growers to gain more for high head rice yield. Three of Egyptian varieties Sakha 106, Giza 179 and Hybridl were grown during 2015 to estimate the total milling yield and grain breakage at five different harvest times \{22, 25, 28, 31 and 34 days after $50 \%$ of flowering (DAF)\}.It was concluded that the highest total milling yield and lowest grain breakage was obtained at the 28, 25 and 31 day after 50\% of the flowering for Sakha 106, Giza 179 and Hybridl respectively. So harvest management preserves rice quality that contribute directly to profit, and then rice growers must harvest rice as carefully as they grow it. Although this study showed that harvesting time is very important, there are many factors have effect on milling quality. Among of these that were investigated is the harvesting time.
\end{abstract}

\section{INTRODUCTION}

ice (Oryza sativa L.) is one of the main food sources in the
world`s people diet. According to the FAO reports, nearly 161.3
million hectares were under cultivation of rice with the total yield of 749.7 million tons in the world in year 2016, (FAO, 2016) and ranked at third place after maize and wheat. It is undergone several processes from harvesting till supplying to the market in the form of white rice. The final quality of white rice is influenced by these processes. The unit value of rice is based primarily on its head rice yield, the proportion of kernels greater than $75 \%$ of intact length; USDA-FGIS, (1994). Improving head rice yield is an ongoing goal for rice growers. Usually, the price of broken milled rice is only 30 to $50 \%$ of the price of head milled rice according to Ntanoset al., (1996).

\footnotetext{
* Researcher, Rice Technology Training Center Alex. Agricultural Research Center.
} 
Less mechanical resistance of rice kernels in milling operation is the key factor for milled rice breakage. Milling is the last stage of milled rice production activities. During this process, the rice grains are subjected to mechanical and thermal stresses are applied to the rice grains. So, some of weak kernels are easily broken Afzaliniaet al., (2004). Milling the rice is an industrial operation which can easily be controlled by right settings the milling machines; so the problems related to milling process, mostly, is determined by the history of the paddy before milling stage Lantin, (1999). The harvest time is a more commonly reported problem. Too early or too late harvesting of rice leads to arise the more immature or cracked kernels, thus resulting in more broken milled rice. Research of Ntanoset al., (1996) indicated that there was an optimum harvest time for each rice cultivar to obtain the highest total milling yield with the lowest milled rice breakage. Hossainet al., (2009) concluded that the suitable harvest time for higher head rice yield of three aromatic rice cultivars of Bangladesh was 30 to 35 (DAF). Sürek and Beşer (1998) showed that the minimum milled rice breakage was obtained at 49 day after flowering in Turkey. Malik et al., (1981) studied the effects of harvest time and drying methods on milling quality of rice. Maximum head rice recovery for Basmati 370 and IR 6-945 cultivars were achieved at 34 DAF and for Basmati 198 cultivar was attained at 40 day after flowering.

Ilievaet al., (2009) reported that the optimum time for harvest is when the moisture content in grain is between 18 and $20 \%$. In all examined varieties they received significantly lower milling yield when paddy was harvested with moisture content above $20 \%$ and below $18 \%$.

In research of Bautista et al., (2009) the optimal harvest moisture content for long-grain cultivars generally is ranged from 18 to $22 \%$ and 19 to 20 $\%$ for medium-grain cultivars. Similar results of these reported Bautista and Siebenmorgen, (2008). Siebenmorgenet al., (2007) reported that head rice yield is a quadratic function of harvest moisture content, which implies that there exists an optimal harvest moisture content to maximize head rice yield. The optimal harvest moisture content differs depending on cultivar and growing location. They recommend optimal harvest moisture content 18.7 to $23.5 \%$ for long-grains varieties and 21.5 to 24.0 $\%$ for medium-grains varieties. 
They recommended that paddy should be harvested at optimum grain maturity at which the grains have an average moisture content of 20-25 $\%$. Higher moisture content results in more losses from poor grain quality. Lower moisture content results in more losses from shattering. For safe storage grains need to be dried to below $14 \%$, and seeds should be dried to below $12 \%$. Ideal moisture content for milling is between $12-14 \%$ (IRRI).

According Akowuahet al., (2012), was reported that fissure can occur in the field prior to harvest, harvesting, processing and storage. Knowledge about the influence of moisture content in paddy in the moment of harvest and time of paddy storage after harvest, on yield and quality of white rice is extremely important, especially in defining the specific recommendations before and after harvest management with yield and quality of white rice in different rice varieties. The objective of the current work is to investigate the optimum harvesting time for three different cultivars of Egyptian rice. This will be based on the maximum milling yield for each variety.

\section{MATERIALS AND METHODS}

This research was conducted at the laboratory of Rice Technology Training Center (RTTC) Alexandria Egypt. Three Egyptian paddy rice varieties Sakha 106, Giza 179 (as short grains) and Hybrid 1 (long grains) were used in this study at five time harvesting time 22, 25, 28, 31 and 34 days after fifty percent flowering for each variety in four replications.

This Egyptian varieties grown in experimental and Agricultural Research Station, Faculty of Agriculture, Alexandria University, during the growing season2015. Amounts of four kilogram for every variety were harvested. Rice grain samples were harvested manually from each variety. The samples were subjected to drying to achieve to about $14 \% \pm 0.5$ moisture content wet basses to be suitable for milling process by A Satake testing dryer (TDR-24A).

\section{Milling process}

1- Cleaning:

Paddy rice was mechanically cleaned to remove foreign materials such as straw, soil particles. Mud balls and weed seeds according to the different 
shape, size and specific weight. Cleaning was done by electric apparatus; namely, Carter-Day Dockage Test model (TGR).The apparatus consist of four oscillating and replicable sieves. The process was completed after three pass.

2- Grading:

The paddy which was obtained from the cleaning apparatus was sorted by testing thickness grader model (TWS). Immature rough rice grains of less thickness than $1.6 \mathrm{~mm}$ are separated out through $1.6 \mathrm{~mm}$ slot mesh sieves.

3- Mixing and dividing:

The Sample Divider model (TS-L) was used to obtain equal and unbiased samples. The paddy was placed in the hopper of capacity of 3 kilograms at the top. When the paddy falls, it is divided into 36 separated streams, merging into 2 streams.

4- hulling:

The first step in the actual rice milling operation is removing hulls to obtain brown rice. Therefore, a Satake laboratory rubber roll huller model (THU-35A) with a capacity of $40 \mathrm{~kg} / \mathrm{hr}$. It was used to hull all samples of paddy rice. From the outside we can confirm the husking condition. Brown rice, husks and immature paddy are separated by an aspirator automatically.

5- milling:

A Satake Testing Mill (TM-05), with an input capacity of 200 grams of brown rice in one time, was used. This whitening machine consists of abrasive roll $\neq 36$ is of $20 \mathrm{~cm}$. diameter and rotate at a speed of $450 \mathrm{rpm}$. The rotate inside a fixed cylinder is of $22 \mathrm{~cm}$. diameter made of perforated steel. The bran layer is removed from the brown rice as a result of friction between rice kernels and both cylinders.

\section{Milling recovery characteristics:}

\section{1- Hulling percentage (\%):}

Three paddy samples (150 gm each) at $14 \%$ moisture content were taken randomly from each sub-plot after threshing and cleaning than dehulled with the experimental Satake huller machine at Rice Technology and Training Center, Alexandria. After that, the brown rice was separated and weighed. The hulling $\%$ was estimated as follows:

$$
\text { Hulling }(\%)=\frac{\text { Brown rice weight }}{\text { Rough rice weight }} \times 100
$$


2- Total milled rice percentage $(\%)$ :

The resulted brown rice from the aforementioned samples was milled by using milling machine model TMO5 at the Rice Technology and Training Center, Alexandria. The total milled rice was weighed and the total milled rice \% was calculated by the following equation:

$$
\text { Total milled rice }(\%)=\frac{\text { Milled rice weight }}{\text { Rough rice weight }} \times 100
$$

3- Broken rice percentage (\%):

Broken milled rice grains were separated from the total milled rice by using sieving device. Then, the percentage of broken rice was obtained and calculated as follows:

$$
\text { Broken }(\%)=\frac{\text { Broken grains milled weight }}{\text { Total milled sample weight }} \times 100
$$

\section{RESULTS AND DISCUSSION}

Data harvest time on milling yield $\%$, head rice $\%$ and rice breakage for three rice varieties Sakha 106, Giza 179 and Hybrid 1 were shown in table (1).

Table (1): The predicted head rice $\%$ as affected by the interaction between harvest time and three rice varieties Sakha 106, GIza 179 and

\begin{tabular}{|c|c|c|c|c|c|c|c|c|c|}
\hline \multirow{3}{*}{$\begin{array}{c}\text { Date of } \\
\text { haevesting }\end{array}$} & \multicolumn{9}{|c|}{ Grain quality property } \\
\hline & \multicolumn{3}{|c|}{$\begin{array}{c}\text { Average milling yield } \\
\% \% \text { yield } \%\end{array}$} & \multicolumn{3}{|c|}{ Head rice yield $\%$} & \multicolumn{3}{|c|}{ Milled rice breakage $\%$} \\
\hline & $\begin{array}{c}\text { Sakha } \\
106\end{array}$ & $\begin{array}{c}\text { Giza } \\
179\end{array}$ & $\begin{array}{l}\text { Hybri } \\
\text { d1 }\end{array}$ & $\begin{array}{l}\text { Sakh } \\
\text { a } 106\end{array}$ & $\begin{array}{l}\text { Giza } \\
179\end{array}$ & $\begin{array}{c}\text { Hybri } \\
\text { d1 }\end{array}$ & $\begin{array}{l}\text { Sakh } \\
\text { a } 106\end{array}$ & $\begin{array}{c}\text { Giza } \\
179\end{array}$ & $\begin{array}{c}\text { Hybrid } \\
1\end{array}$ \\
\hline $\begin{array}{l}22 \text { day after } \\
\text { flowering }\end{array}$ & 68.68 & 67.83 & 66.02 & 59.18 & 59.59 & 57.37 & 9.50 & 8.24 & 8.65 \\
\hline $\begin{array}{l}25 \text { day after } \\
\text { flowering }\end{array}$ & 69.40 & 69.57 & 68.11 & 61.45 & 62.73 & 60.71 & 7.95 & 6.84 & 7.40 \\
\hline $\begin{array}{l}28 \text { day after } \\
\text { flowering }\end{array}$ & 71.18 & 69.22 & 69.15 & 65.29 & 62.12 & 63.25 & 5.89 & 7.10 & 5.90 \\
\hline $\begin{array}{l}31 \text { day after } \\
\text { flowering }\end{array}$ & 70.82 & 69.29 & 69.50 & 64.49 & 60.69 & 63.80 & 6.33 & 8.60 & 5.70 \\
\hline $\begin{array}{l}34 \text { day after } \\
\text { flowering }\end{array}$ & 67.62 & 68.17 & 67.76 & 59.82 & 59.02 & 61.26 & 7.80 & 9.15 & 6.50 \\
\hline
\end{tabular}
Hybried1. 


\section{Average milling yield \%}

Data in figure (1) showed that milling yield \% in Sakha 106, Giza 179 and Hybrid 1 rice variety as affected by date of harvesting time after 50\% of the flowering.
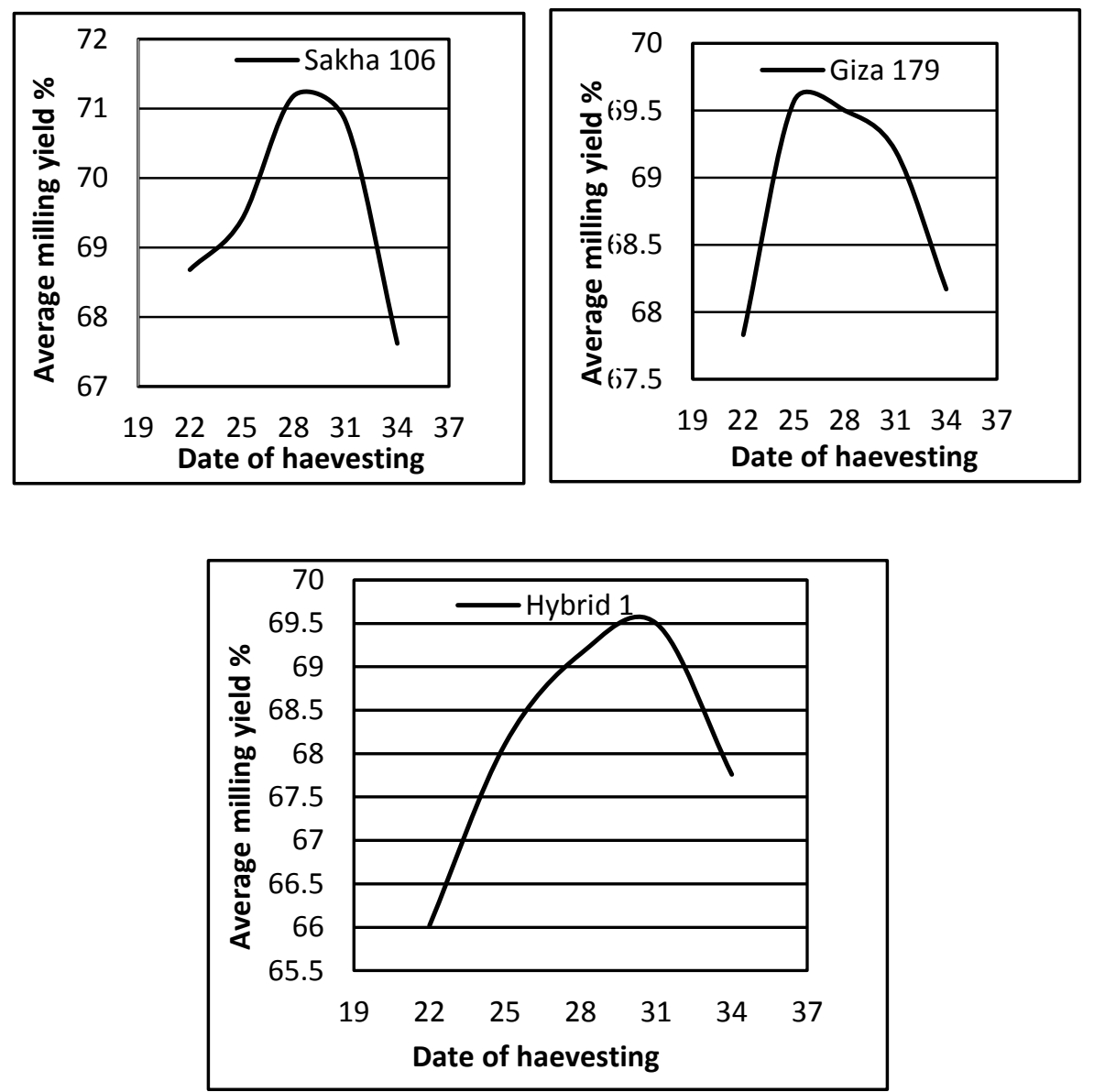

Figure (1): Milling yield \% for Sakha 106, Giza 179 and Hybrid1 rice variety as affect by date of harvesting time after $50 \%$ of the flowering.

The relationship between date harvest timeafter $50 \%$ of the flowering and the milling yield \% for rice variety Sakha 106 can be expressed in the equation:

Milling yield \% $($ Sakha 106 $)=0.012 M^{3}+0.9319 M^{2}-23.531 M+263.44$

Where: $\mathbf{M}$ is the date of harvesting time after $50 \%$ of the flowering. 
with the $\mathbf{R}^{2}=\mathbf{0 . 9 8 9 8}$

From the mathematical equation which described the relationship shows the importance of date of harvesting time after $50 \%$ of the flowering on milling yield $\%$ in range. The obtained data showed that, the date of harvesting time (28 day date of harvesting time after $50 \%$ of the flowering) gives milling yield highest.

Data in figure (1) showed that milling yield \% in Giza 179 rice variety as affected by date of harvesting time after $50 \%$ of the flowering.

The relationship between date harvest time after $50 \%$ of the flowering and the milling yield $\%$ for rice variety Giza 179 can be expressed in the equation:

Milling yield \% $\left(\right.$ Giza 179) $=0.0033 \mathrm{M}^{3}-0.3258 \mathrm{M}^{2}+10.313 \mathrm{M}-\mathbf{3 6 . 9 3 1}$

Where: $\mathbf{M}$ is the date of harvesting time after $50 \%$ of the flowering. with the $\mathbf{R}^{2}=\mathbf{0 . 9 7 5 9}$

From the mathematical equation which described the relationship shows the importance of date of harvesting time after $50 \%$ of the flowering on milling yield $\%$. The obtained data showed that, the date of harvesting time ( 25 day date of harvesting time after $50 \%$ of the flowering) gives milling yield \% highest.

Data in figure (1) showed that milling yield \% in Hybrid 1 rice variety as affected by date of harvesting time after $50 \%$ of the flowering. The relationship between date harvest time after $50 \%$ of the flowering and the milling yield $\%$ can be expressed in the equation:

Milling yield \% $($ Hybrid 1 $)=0.0032 M^{3}+0.2034 M^{2}-3.578 M+80.513$

Where: $\mathbf{M}$ is the date of harvesting time after $50 \%$ of the flowering.

with the $\mathbf{R}^{2}=\mathbf{0 . 9 9 4 1}$

From the mathematical equation which described the relationship shows the importance of date of harvesting time after $50 \%$ of the flowering on milling yield $\%$. The obtained data showed that, the date of harvesting time (31 day date of harvesting time after $50 \%$ of milling yield \%highest. 


\section{Head rice yield \%}

Data in figure (4) showed that head rice percentage in Sakha 106, Giza 179 and Hybrid1 rice variety as affected by date of harvesting time after $50 \%$ of the flowering.
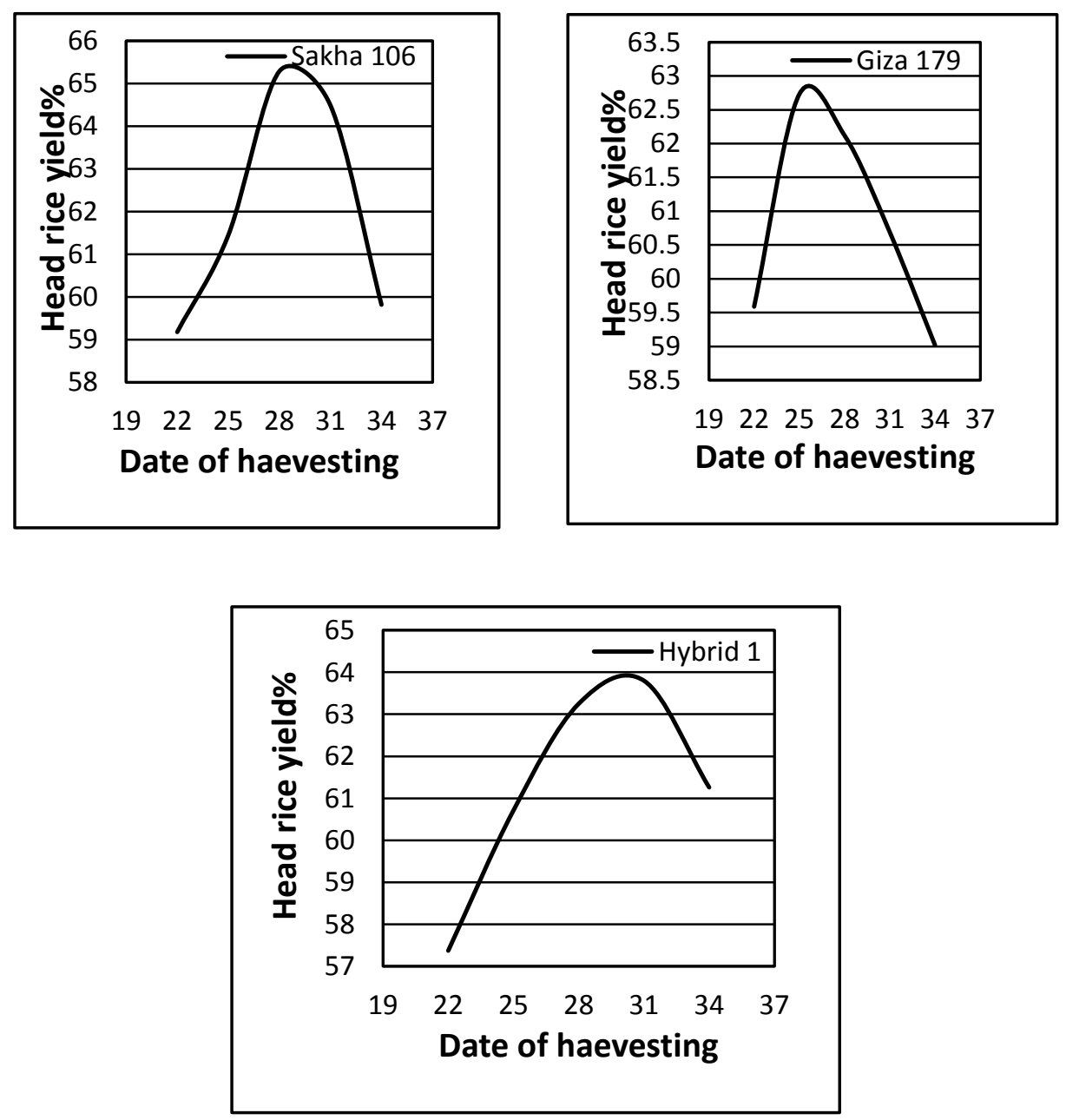

Figure (2): Head rice \% for Sakha106, Giza 179 and Hybrid1 rice variety as affect by date of harvesting time after $50 \%$ of the flowering.

The relationship between date harvest timeafter $50 \%$ of the flowering and the head rice percentage for rice variety Sakha 106 can be expressed in the equation:

Head rice \% $($ Sakha 106 $)=0.0168 M^{3}+1.2634 M^{2}+30.601 M+299.62$ 
Where: $\mathbf{M}$ is the date of harvesting time after $50 \%$ of the flowering. with the $\mathbf{R}^{2}=\mathbf{0 . 9 7 6 8}$

From the mathematical equation which described the relationship shows the importance of date of harvesting time after $50 \%$ of the flowering on head rice $\%$. The obtained data showed that, the date of harvesting time (28 day date of harvesting time after $50 \%$ of the flowering) gives the lowest grain breakage and highest head rice percentage. Data in figure (2) showed that head rice percentage in Giza 179 rice variety as affected by date of harvesting time after $50 \%$ of the flowering. The relationship between date harvest time and the head rice percentage for Giza 179 can be expressed in the equation:

Head rice \% $\left(\right.$ Giza 179) $=0.0108 M^{3}+0.9929 M^{2}+29.683 M-228.2$

Where: $\mathbf{M}$ is the date of harvesting time after $50 \%$ of the flowering. with is $\mathbf{R}^{\mathbf{2}}=\mathbf{0 . 9 9 2 2}$

From the mathematical equation which described the relationship shows the Importance of date of harvesting time after $50 \%$ of the flowering on head rice $\%$. The obtained data showed that, the date of harvesting time (25 day date of harvesting time after $50 \%$ of the flowering) gives the lowest grain breakage and highest head rice percentage. Data in figure (2) showed that head rice percentage in Hybrid1 rice variety as affected by date of harvesting time after 50\% of the flowering. The relationship between harvest moisture content percentage and the head rice percentage for Hybrid 1 rice variety can be expressed in the following equation:

\section{Head Rice \% (Hybrid 1) $=0.0071 M^{3}+0.4846 M^{2}-9.934 M+116.64$}

Where: $\mathbf{M}$ is the date of harvesting time after $50 \%$ of the flowering.

With the $\mathbf{R}^{2}=\mathbf{0 . 9 9 9 8}$

From the mathematical equation which described the relationship shows the Importance of date of harvesting time after $50 \%$ of the flowering on head rice $\%$. The obtained data showed that, the date of harvesting time (31 day date of harvesting time after $50 \%$ of the flowering) gives the lowest grain breakage and highest head rice percentage.

\section{Grain breakage \%}

Data in figure (3) showed that Grain breakage \% in Sakha 106, Giza 179 and Hybrid 1 rice variety as affected by date of harvesting time after $50 \%$ of the flowering. 

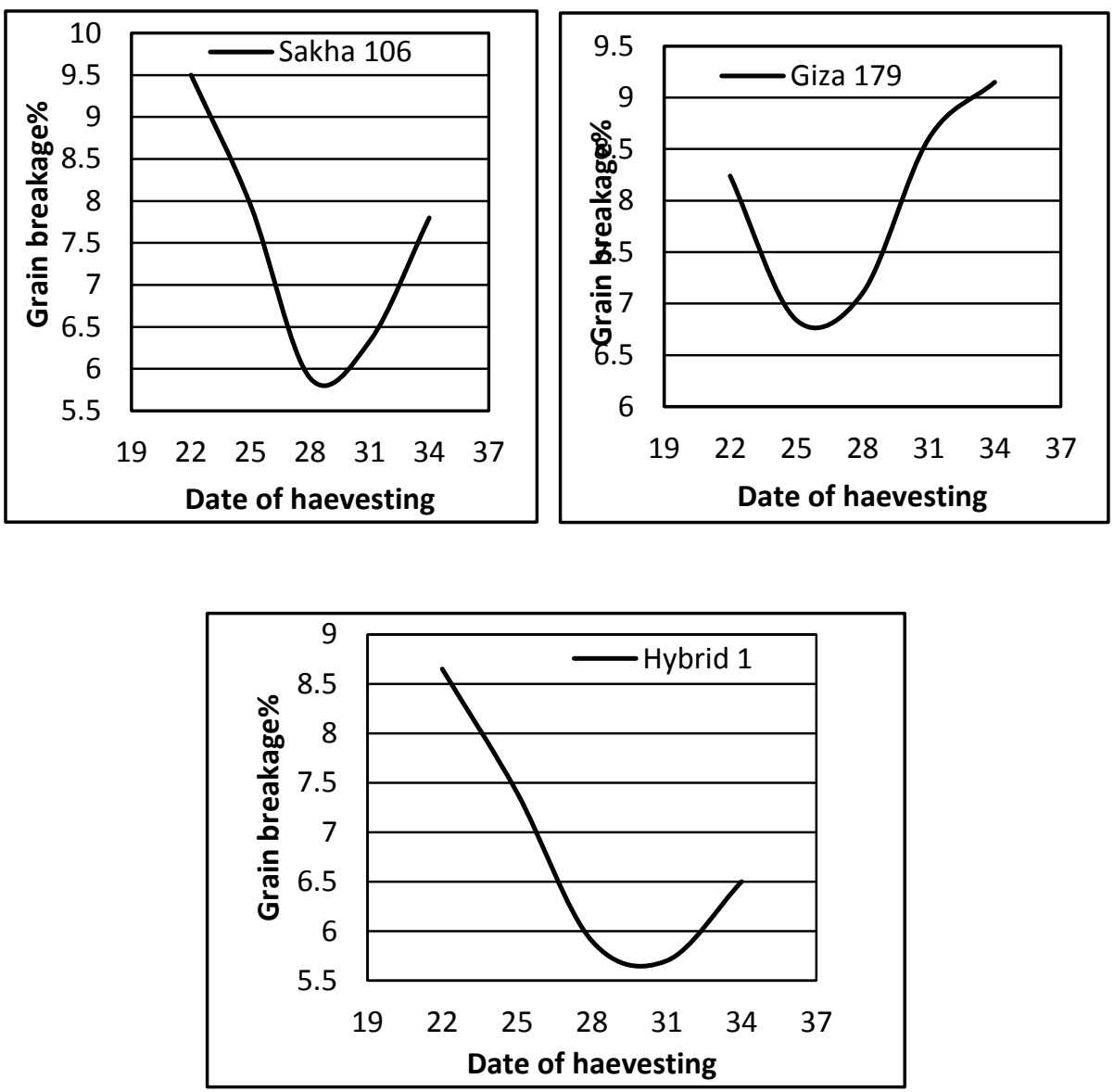

Figure (3): Grain breakage \% for Sakha 106, Giza 179 and Hybrid1 rice variety as affect by date of harvesting time after $50 \%$ of the flowering.

The relationship between date harvest time after $50 \%$ of the flowering and the Grain breakage \% for Sakha 106 rice variety can be expressed in the following equation:

Head Rice \% $\left(\right.$ Sakha 106) $=0.0048 M^{3}-0.3315 M^{2}+7.0709 M-36.17$

Where: $\mathbf{M}$ is the date of harvesting time after $50 \%$ of the flowering. With the $\mathbf{R}^{2}=\mathbf{0 . 9 6 5 3}$

From the mathematical equation which described the relationship shows the importance of date of harvesting time after $50 \%$ of the flowering onGrain breakage \%. The obtained data showed that, the date of harvesting time (28 day date of harvesting time after $50 \%$ of the flowering) gives the lowest grain breakage and highest head rice 
percentage. Data in figure (3) showed that Grain breakage \% in Giza 179 rice variety as affected by date of harvesting time after $50 \%$ of the flowering. The relationship between date harvest time after $50 \%$ of the flowering and the Grain breakage \% for Giza 179 rice variety can be expressed in the following equation:

Head Rice \% $($ Giza 179 $)=0.0081 M^{3}+0.7175 M^{2}-\mathbf{2 0 . 8 6 5} M+205.83$

Where: $\mathbf{M}$ is the date of harvesting time after $50 \%$ of the flowering. With the $\mathbf{R}^{\mathbf{2}}=\mathbf{0 . 9 8 8 5}$

From the mathematical equation which described the relationship shows the importance of date of harvesting time after $50 \%$ of the flowering on Grain breakage $\%$. The obtained data showed that, the date of harvesting time ( 25 day date of harvesting time after $50 \%$ of the flowering) gives the lowest grain breakage and highest head rice percentage. Data in figure (3) showed that Grain breakage \% in Hybrid 1 rice variety as affected by date of harvesting time after $50 \%$ of the flowering. The relationship between harvest moisture content percentage and the Grain breakage \% for Hybrid 1 rice variety can be expressed in the following equation:

Head Rice \% (Hybrid 1) = 0.0039 $\mathrm{M}^{3}$ - 0.2812 $\mathrm{M}^{2}+\mathbf{6 . 3 5 6} \mathrm{M}$ - 36.127

Where: $\mathbf{M}$ is the date of harvesting time after $50 \%$ of the flowering.

With the $\mathbf{R}^{2}=\mathbf{0 . 9 9 1 7}$

From the mathematical equation which described the relationship shows the importance of date of harvesting time after $50 \%$ of the flowering on Grain breakage \%. Data in figure (3) showed that Grain breakage \% in Hybrid 1 rice variety as affected by date of harvesting time. The obtained data showed that, the date of harvesting time (31 day date of harvesting time after $50 \%$ of the flowering) gives the lowest Grain breakage \%.

Table (2) Data cleared that, the highest head rice percentage was obtained when Sakha 106 rice variety harvester at 28 day date of harvesting time after $50 \%$ of the flowering which gives about $65.29 \%$ head rice, but when Giza 179 rice variety harvested at 25 day date of harvesting time after $50 \%$ of the flowering gives also about $62.73 \%$ head rice, while Hybrid 1 rice variety gives $63.80 \%$ of head rice when harvested at 31 day date of harvesting time after $50 \%$ of the flowering.

Thetreatments means were compared using the least significant difference test(LSD) at 5\% probability level according to CoHort software (2005). 
Table (2): The head rice $\%$ as affected by the interaction between harvest time and three rice varieties Sakha 106, GIza 179 and Hybried1.

\begin{tabular}{|c|c|c|c|}
\hline \multirow{2}{*}{ Harvest time } & \multicolumn{3}{|c|}{ Head rice yield \% } \\
\hline & Sakha 106 & Giza 179 & Hybrid1 \\
\hline 22 day after flowering & $59.18 \mathrm{f}$ & $59.59 \mathrm{~d}$ & $57.37 \mathrm{f}$ \\
\hline 25 day after flowering & $61.45 \mathrm{c}$ & $62.73 \mathrm{a}$ & $60.71 \mathrm{c}$ \\
\hline 28 day after flowering & $65.29 \mathrm{a}$ & $62.12 \mathrm{~b}$ & $63.25 \mathrm{~b}$ \\
\hline 31 day after flowering & $64.49 \mathrm{~b}$ & $60.66 \mathrm{c}$ & 63.80 a \\
\hline 34 day after flowering & $59.82 \mathrm{~d}$ & $59.02 \mathrm{f}$ & $61.26 \mathrm{~d}$ \\
\hline L.S.D 0.05 & 0.230 & 0.209 & 0.185 \\
\hline
\end{tabular}

\section{CONCLUTION}

The highest total milling yield and lowest grain breakage was obtained at the 28, 25 and 31 day after 50\% of the flowering for Sakha 106, Giza 179 and Hybrid1 respectively.All the quality parameters average milling yield $\%$, Head rice yield $\%$ and milled rice breakage were significant affected by the interaction of harvesting time and variety.

The available data were utilized to come up with regression equations that tie the three dependent variable (average milling yield \%, head rice yield $\%$ and milled rice breakage $\%$ ) with the harvesting time. This can be used to maximize these variables as affected by the date of harvest.

\section{REFERENCES}

Afzalinia S, Shaker M, and Zare E. 2004.Comparison of different rice milling methods.Canadian Biosystems Engineering 46(3), 63-66.

Akowuah, J. O., Addo, A., and Bart-Plange, A. 2012. Influence of drying temperature and storage duration on fissuring and milling quality of Jasmine 85 rice variety. Journal of Science and Technology, 32(2): 26-33.

Bautista, R.C., and Siebenmorgen,T.J. 2008. Estimating Rice Optimal Harvest Moisture Content Using Individual Kernel Moisture Content Distributions at Harvest. 
Bautista, R.C., T.J. Siebenmorgen and A. Mauromoustakos 2009.The role of rice individual kernel moisture content distributions at harvest on milling quality. Trans. of the ASABE 52 (5): 1611-1620.

Hossain MF, Bhuiya MSU, Ahmed M, and Mian MH. 2009. Effect of harvesting time on the milling and physicochemical properties of aromatic rice. Thailand Journal of Agricultural Science 42(2), 9196.

http://www.fao.org/economic/est/publications/rice-publications/ricemarket-monitor-rmm/en/

IlievaVerica, AndreevskaDanica, AndovD.,MarkovaNatalija, and JankulovskaMirjana 2009.Dressing percentage of white rice in correlation with the harvest time of the rice. Yearbook of the Faculty of Agricultural Sciences and Food, Skopje. Vol. 54, p. 1927.

IRRI - available at http://www.knowledgebank.irri.org

Lantin R. 1999. RICE: Post-harvest Operations. International Rice Research Institute, Philippines (IRRI), 62 p.

Malik A, Majid A, and Ahmad S. 1981.Effect of harvesting time and drying method on paddy yield and milling quality in different varieties. Pakistan Journal of Agricultural Research 2(1), 7-12.

Ntanos D, Philippou N, and Hadjisavva-Zinoviadi S. 1996.Effect of rice harvest time on milling yield and grain breakage. Cahiers Options Méditerranéennes 15(1), 23-28.

Siebenmorgen, T.J., R.C. Bautista, and P.A. Counce. 2007. Optimal harvest moisture contents for maximizing rice milling quality. Appl. Eng. Agric. 23(4):517-527.

SürekH, and Beşer N.1998. A research to determine the suitable rice (oryza sativa L.) harvesting time. TÜBITAK, Turkish Journal of Agriculture and Forestry 22, 391-394.

USDA-FGIS. 1994. Rice inspection handbook. Washington D.C.:USDA Agricultural Marketing Service. 


\section{الملخص العربيى}

\section{تأثير وقت الحصاد على معدلات التبيضض والكسر لأصناف أرز شعير مصرية} د. محمد السيد عمر يحيى * و د. احمد رمضان ابراهيم خطاب*

من الأشياء الغير جيدة الفهم ناثير وقت الحصاد على الصفات الحسية والفيزوكيمائية للأرز.

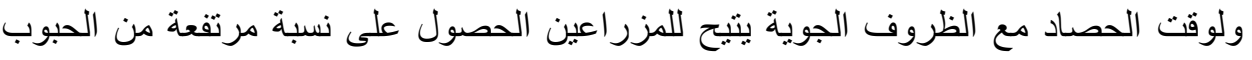

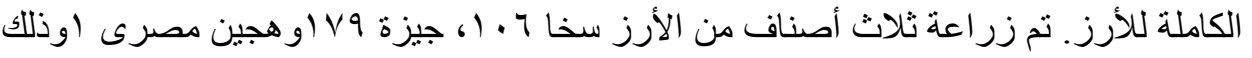

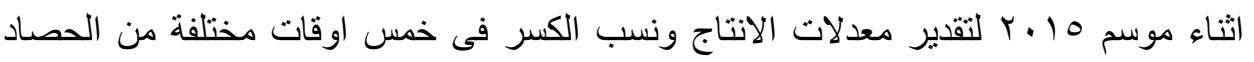

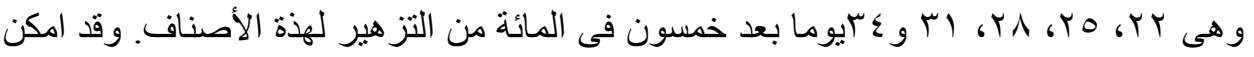

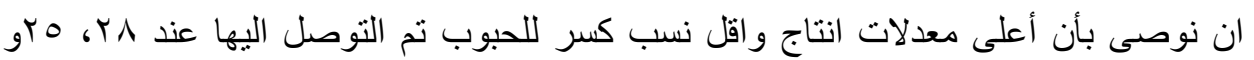

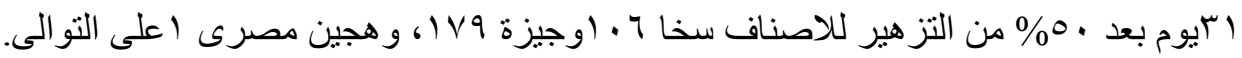

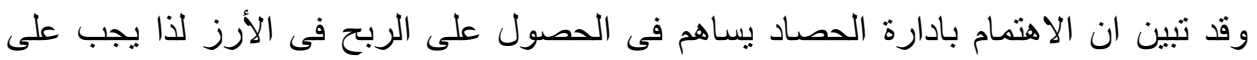

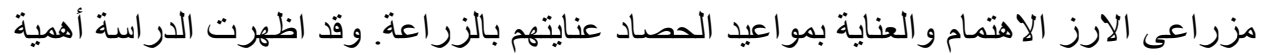

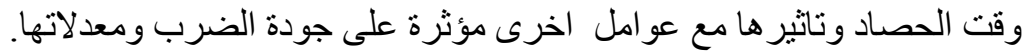

